\title{
Application of PedsQLTM Questionnaires to the Evaluation of Quality of Life in Families with Children with Selected Diagnoses
}

\author{
I. Baloun (Ingrid Baloun), M. Veleminsky (Milos Veleminsky), 0. Dvorackova \\ (Olga Dvorackova)
}

University of South Bohemia in Ceske Budejovice, Faculty of Health and Social Sciences, Institute of Laboratory Diagnostics and Public Health, Ceske Budejovice, Czech Republic

\section{E-mail address:}

ingrid.baloun@gmail.com

\section{Reprint address:}

Ingrid Baloun

University of South Bohemia in Ceske Budejovice

Faculty of Health and Social Sciences

Ceske Budejovice

Czech Republic

Source: Clinical Social Work and Health Intervention

Pages: $86-102$
Volume: 10

Issue: 3

Cited references: 13

\section{Reviewers:}

Clauss Muss

I-GAP Vienna, AT

Zofia Szarota

Pedagogical University of Cracow, PL

\section{Keywords:}

PedsQL ${ }^{\mathrm{TM}}$; Quality of life; Diabetes Mellitus; Autistic Spectrum Disorder; Combined handicap; ADHD.

\section{Publisher:}

International Society of Applied Preventive Medicine i-gap

CSWHI 2019; 10(2): 86 - 102; DOI 10.22359/cswhi_10_3_03 (c) 2019 Clinical Social Work and Health Intervention 


\section{Abstract:}

The evaluation of the quality of life is an important component of considering biopsychosocial situations in children suffering from chronic diseases.

\section{Design: Pilot study}

The sample group and methods: Children with diagnoses Diabetes Mellitus, Autistic Spectrum Disorder (ASD), Attention Deficit Hyperactivity Disorder (ADHD) and Cerebral Palsy (CP) were monitored together with their parents. The control group comprised ten healthy children and their parents. PedsQL questionnaires, marked PedsQL 4.0, PedsQL 2.0 - family module, were employed. The so called survey questionnaire was used for the quantitative research. The qualitative research was implemented with the help of a semi-structured dialogue with parents. The statistical processing was based on non-parametric Kruskal-Wallis Tests/for independent sampling) and Wilcoxon Test (paired comparison).

In all the tests, the significance level $(\alpha)$ of 0.05 was chosen. The qualitative research was processed by the Atlas.ti program with establishing 600 open codes and with origination of nine categories.

Conclusion: Differences in the score axis in five groups of respondents resulted in refusing the zero hypothesis $\mathrm{H} 0$, i.e. the results were different throughout the questionnaires. The results of five paired subgroups demonstrated that there were most frequent differences between controls and subgroups of children with autism and ADHD. Results of the qualitative research are summarized in the section Results. PedsQL ${ }^{\mathrm{TM}}$ questionnaires were applicable to all the families. Children with the autistic spectrum disorder encountered problems with the PedsQL ${ }^{\mathrm{TM}}$ questionnaire - they were unable to complete the questionnaire and they did not understand the questionnaire scale.

\section{Introduction}

"WHO defines Quality of Life as individualsZ perception of their position in life in the context of the culture and value systems in which they live and in relation to their goals, expectations, standards and concerns." (The WHOQOL ..., p.1).

The PedsQL 4.0 questionnaire, generic module includes a total of 23 questions (Varni, 2001). PedsQL 4.0 questionnaires have four subscales: Physical health, emotional health, social activities and school activities (Baloun, Velemínský, 2018). The Paediatric Quality of Life Inventory ${ }^{\mathrm{TM}}$ (henceforth PedsQL ${ }^{\mathrm{TM}}$ ) comes from James W. Varni (Varni, 2004; Varni et al., 2003). "The PedsQL is a valid, reliable, flexible (applicable in the community, in schools

and in pediatric practice) and multidimensional tool (it consists of 4 subscales - physical, emotional, social function and function in school) measurement of the quality of life" (Gurková, p. 167). There are total of 34 mod- 
ules of PedsQL questionnaires (Cheng et al., 2016).

The PedsQL 4.0 questionnaire is a generic module comprising total of 23 questions divided into four areas (physical health and activities, emotional health, social activities and school activities) (Varni, 2017). This questionnaire has been translated into 109 world languages (ePROVIDE, 2018). The questionnaire is divided by age categories of children (aged 2-4 years, aged 5-7 years, aged 8-12 years and aged 13-18 years) (Burešová et al., 2008).

\section{Methods and Sample Group Characterization}

The sample included 4 types of diseases - Diabetes Mellitus, Autistic Spectrum Disorder (henceforth ASD), Attention Deficit Hyperactivity Disorder (henceforth ADHD) and Cerebral Palsy (henceforth CP). Each category of diseases included five children with their parents. The control group included 10 healthy children with their parents. In the course of the research, the completely anonymous nature of the study was adhered to; numbers were assigned to communication partners, under which they completed the questionnaires.

The research was divided into three parts. In the first part, the parents completed the basic questionnaire, aimed at identification data on the child and family - age, diagnosis, completeness of the family, financial background of the family, etc. In the second part, in the course of personal meetings, children and their parents completed PedsQL ${ }^{\mathrm{TM}}$ questionnaires. The third part was a semi-structured interview with the parents. In the course of the interview, we presented questions, for example that focused on the questionnaire comprehensibility; life story; child diagnosis; course of the treatment; taking advantage of social services.
In the quantitative part, 4 types of PedsQL questionnaires were used - we were the first authors using the generic PedsQL 4.0 questionnaire completed separately by children and by their parents. A further questionnaire used was the PedsQL 2.0 - family module. This module was completed by parents twice - firstly in terms of the last seven days and secondly with respect to the last month. In the PedsQL 4.0 questionnaire, three scales are evaluated: score of physical health; score of psychosocial health; total score (Varni, 1998). In the questionnaire PedsQL 2.0 - family module, the "quality of life in relationship with the health condition" (Health-Related Quality of Life, HRQL); score of the family function; total score were evaluated. In each group, 12 tests were implemented in total of 5 children and 5 parents from each group of diseases and in 10 healthy children and their parents.

A comparison of the score achieved in groups of diseases monitored was provided because of a not normal distribution of the group based on non-parametric Kruskal-Wallis Tests (for independent sampling) and Wilcoxon Tests (paired comparison) (Vargha, Delaney, 1998). The significance level chosen $(\alpha)$ was of 0.05 in all the tests.

The third part of the research was implemented by a qualitative data analysis, particularly by an open coding. The interviews were recorded by a Dictaphone and subsequently literally rewritten. More than 600 codes were obtained by open coding, which were then categorized, and this resulted in 9 categories. Some of categories are accompanied by graphical outputs, which were processed in the ATLAS.ti 8 software program (Friese, 2014). The advantage of this program is that it may be used not only for classing the data but also for graphical processing, which made it possible to accompany the research results by appropriate schemes. The choice of informants for interviews was particularly implemented by using the snowball method and 
partially by aimed intentional choice depending on the child diagnosis.

\section{Results}

\section{Results from the quantitative part of the research \\ The following principal categories were obtained based on the analysis of the data ob- tained:}

\section{- Identification data}

- PedsQL ${ }^{\mathrm{TM}}$ questionnaire

- Diabetes

- ASD

- Combined handicaps

- ADHD

- Social support

- Material support

- Life with child's handicap

\section{Identification data}

Table 1: Gender representation of respondents

The sample of 20 children, in which the quality of life was investigated by using PedsQL ${ }^{\mathrm{TM}}$ questionnaires included total of 8 girls and 22 boys.

\begin{tabular}{|c|c|}
\hline Male & $22 ; 73 \%$ \\
\hline Female & $8 ; 27 \%$ \\
\hline
\end{tabular}

Source: Original research

Table 2: Age representation of respondents

\begin{tabular}{|c|c|}
\hline & Age (years) \\
\hline average & 11.2 \\
\hline modus & 13 \\
\hline median & 11 \\
\hline
\end{tabular}

Source: Original research
The age range was delimited immediately at the beginning of the research and we choose children and adolescents aged 5 to 18 years. This age category was chosen with respect to questionnaires which are divided depending on the child age.

Table 3: Type of school/education

\begin{tabular}{|c|c|}
\hline $\begin{array}{c}\text { Type of school/edu- } \\
\text { cation }\end{array}$ & $\begin{array}{c}\text { Number } \\
\text { of respondents }\end{array}$ \\
\hline Kindergarten & $4 ; 13 \%$ \\
\hline $\begin{array}{c}\text { Primary school - de- } \\
\text { gree } 1\end{array}$ & $13 ; 44 \%$ \\
\hline $\begin{array}{c}\text { Primary school - de- } \\
\text { gree } 2\end{array}$ & $8 ; 27 \%$ \\
\hline Secondary school & $4 ; 13 \%$ \\
\hline Teaching at home & $1 ; 3 \%$ \\
\hline
\end{tabular}

Source: Original research

In children and adolescents, information about the school type (degree) attended was accumulated. Most children attended the primary school. These were the classic type of primary schools as well as special schools.

A total of 30 informants participated in the research, who had a handicapped child. As to their marital status, they were either married or in a partnership relationship with the child's father or with another partner. As to the occupation of the mothers, it is to mention that most of them returned back to the occupation or were on the maternity leave. Taking care of the child was a full time work in three informants only, and in one case, the father took the care of the child. Most fathers have their permanent jobs and were in the bond of marriage.

The children's age ranged between 5 and 18 years and boys were prevalent as to the sex. In the sample studied, we tried to equally cover all the diagnoses established, i.e. ADHD, ASD, combined handicap and diabetes. The complications of handicaps were diverse. 
Scheme 1: Identification data

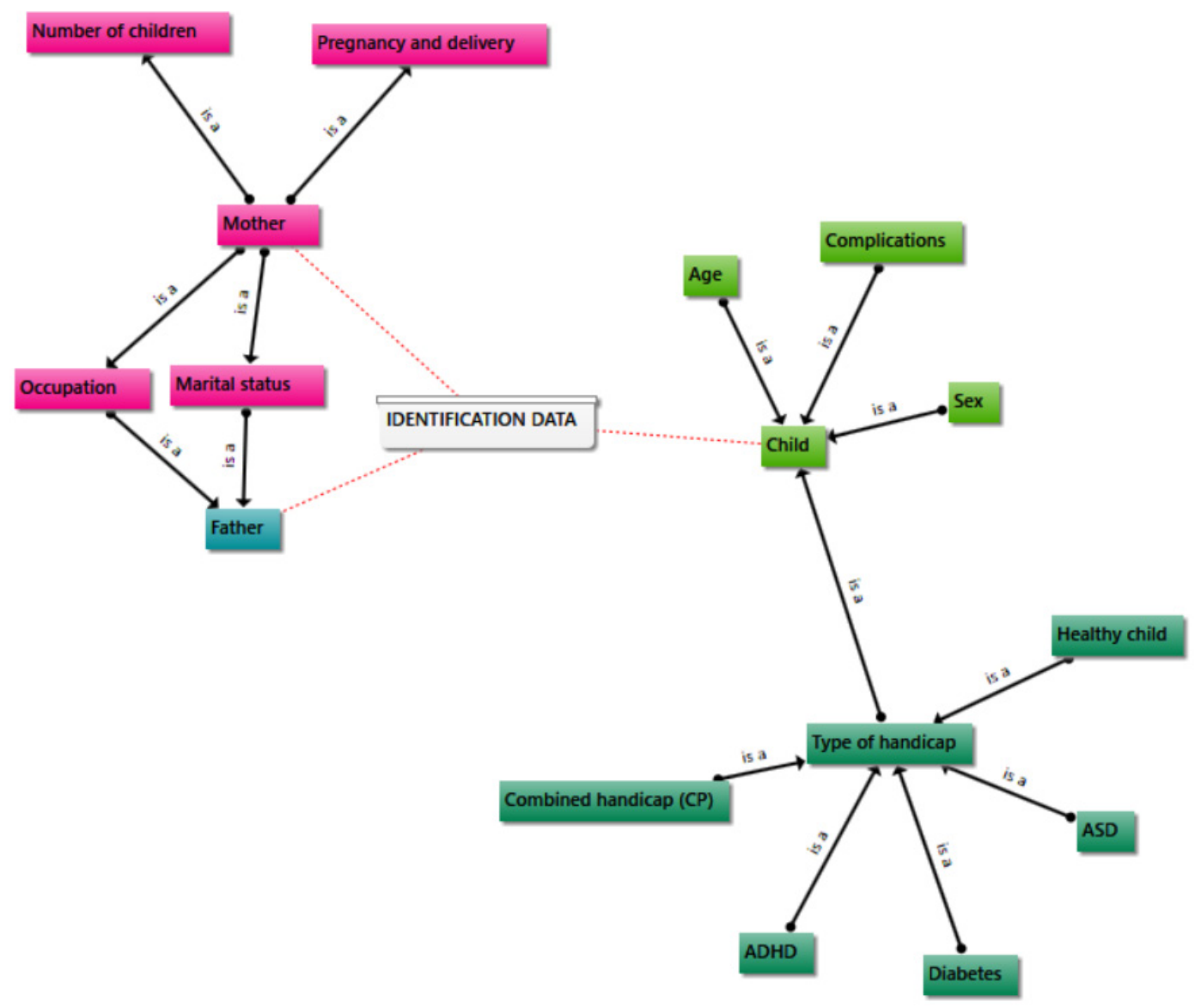

Source: Original research

\section{PedsỌLTM questionnaire}

Scheme 2: PedsQ̣L questionnaire

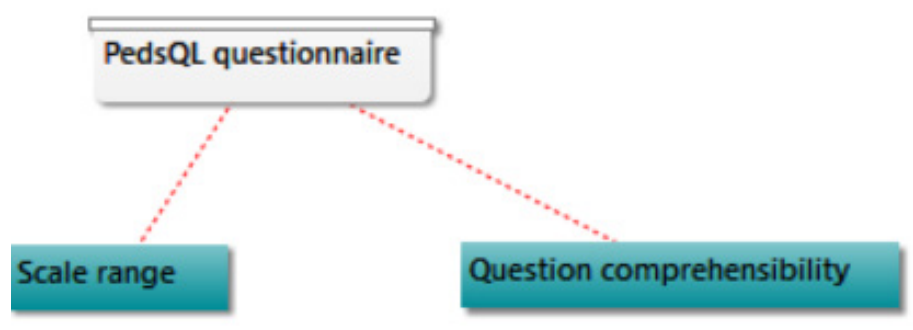

Source: Original research 
Most informants reported that the questions in the questionnaire were well comprehensible, only some of them mentioned moderate unclearness or facts that some questions or responses were vague and too general. The scale range was mostly sufficient, but within the framework of interviews, the informants also proposed that the scale should be reduced to three points in the future, which could facilitate completing of the questionnaire. but also by using an insulin pump and newly also with the help of a special sensor which provides information about the actual sugar level in the blood based on information technologies. However, this is also associated with financial requirements as mentioned by informants whose children have the sensor. A considerable advantage of the sensor is, however, the fact that it is possible to avoid night hypoglycemic conditions as reported by in-

\section{Diabetes Mellitus}

\section{Scheme 3: Diabetes}

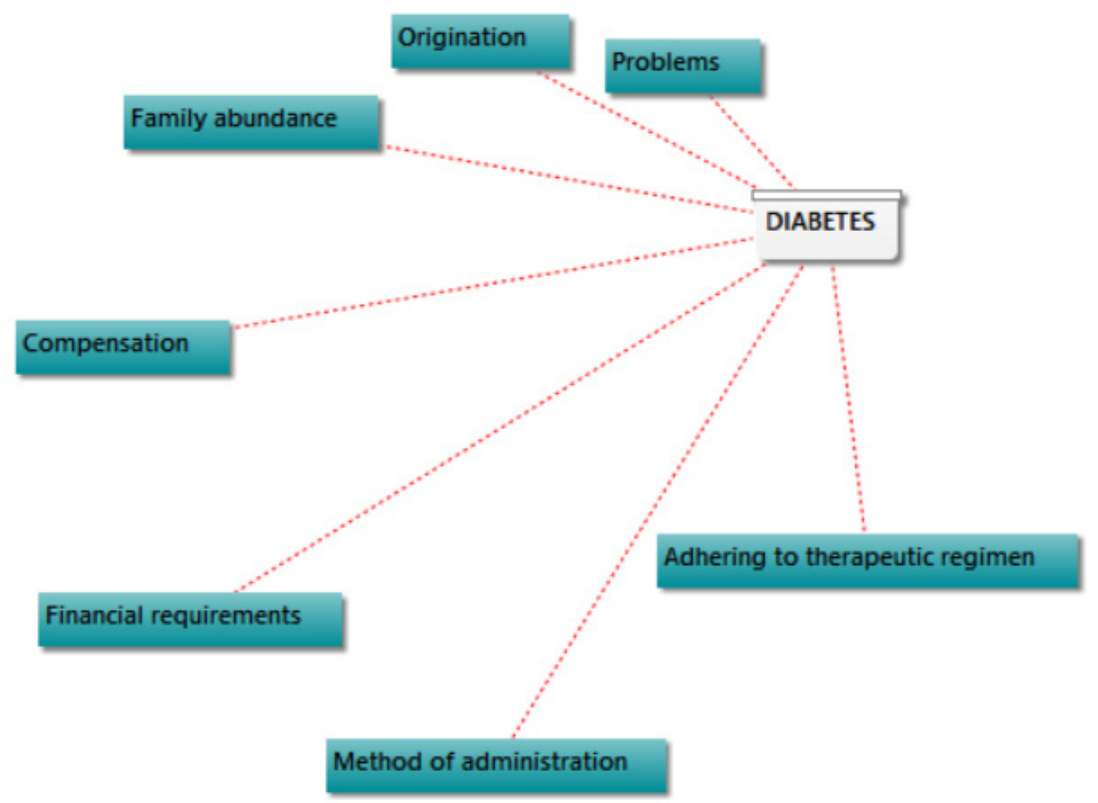

\section{Source: Original research}

Type I Diabetes Mellitus was developed in different periods from the toddler age to the older pupil age and the positive family anamnesis occurred only in two families who submitted to the interview. The necessary insulin administration is most frequently implemented with the use of an insulin pen formant R13. However, children otherwise principally adhere to the therapeutic regimen, though if the informants pointed out failures and bargaining from time to time. This was associated with problems such as taking meals, multiplication of insulin doses or stress. 


\section{Autistic Spectrum Disorders}

Scheme 4: ASD

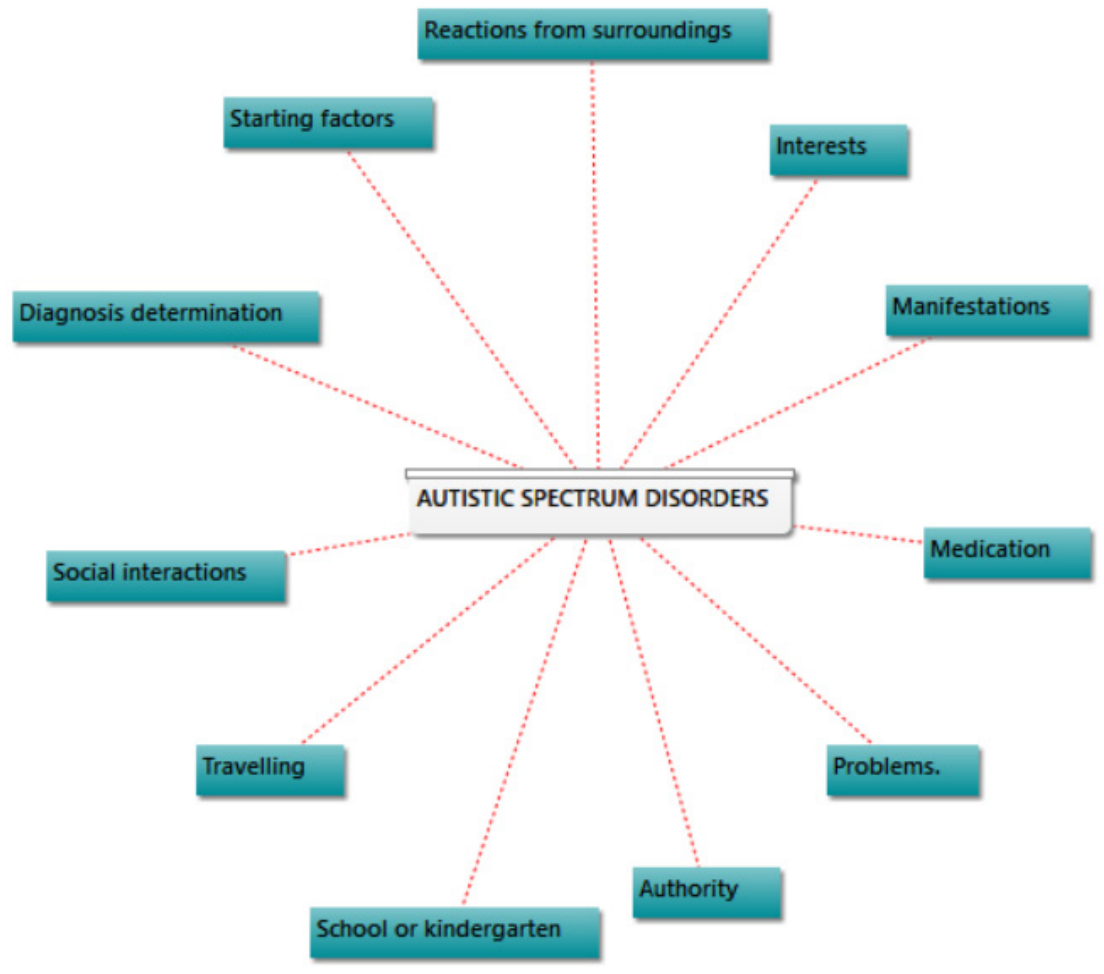

\section{Source: Original research}

Autistic Spectrum Disorders are a very specific diagnosis manifested in a different way in each particular individual. However, based on the communication by informants, the shared manifestations can be considered as fits of temper associated with aggression from time to time; adhering to stereotypes; anxiety; contrastingly hyperactivity. The starting factor is usually a disturbance of rituals, stress, presence of many humans or fatigue. The reactions of the surroundings to manifestations of the child were mentioned by informant R11, who complained about inadequate reactions and considerable misunderstanding in the school or making the problem light in the hospital. In most children, the social interactions are disturbed. They frequently tend to stay beyond the col- lective and any crowd of people is difficult for them.

Based on communications by the informants, the diagnosis was most frequently identified at the pre-school age of the children and first manifestations were observed by mothers as soon as at the suckling or toddler age. The children from the research sample attend special or practical school; only the son of informant R11 attends the common type of the school with the help of assistants. The favored activity of children is travelling - they enjoy travelling based on information from their mothers. Interest in technical things, such as trolleybus, telephone or computer is mentioned. Lego is also of interest but every child has also his/her specific hobby, as for example the son of informant R27 enjoys following the 
construction of superhighways and inspects milestones.

This diagnosis in the children is, however, associated with different problems as for example with society; problems associated with the rhythm of the child such as refusal or stereotypes in food; sleeping problems; sensitivity to sounds; problems with the locomotor activity; considerable moodiness; alternation of worse and better periods. the children, the handicaps originated prenatally or perinatally. In the case of the perinatal development, these were problems in the course of the delivery with origination of hypoxia or in association with an incorrect conduction of the delivery. In one of the children, the prenatal origination was affected by cerebral aneurysm. Combined handicaps are also associated with many problems. Informants mentioned health as well as social problems

\section{Combined handicaps}

Scheme 5: Combined handicaps

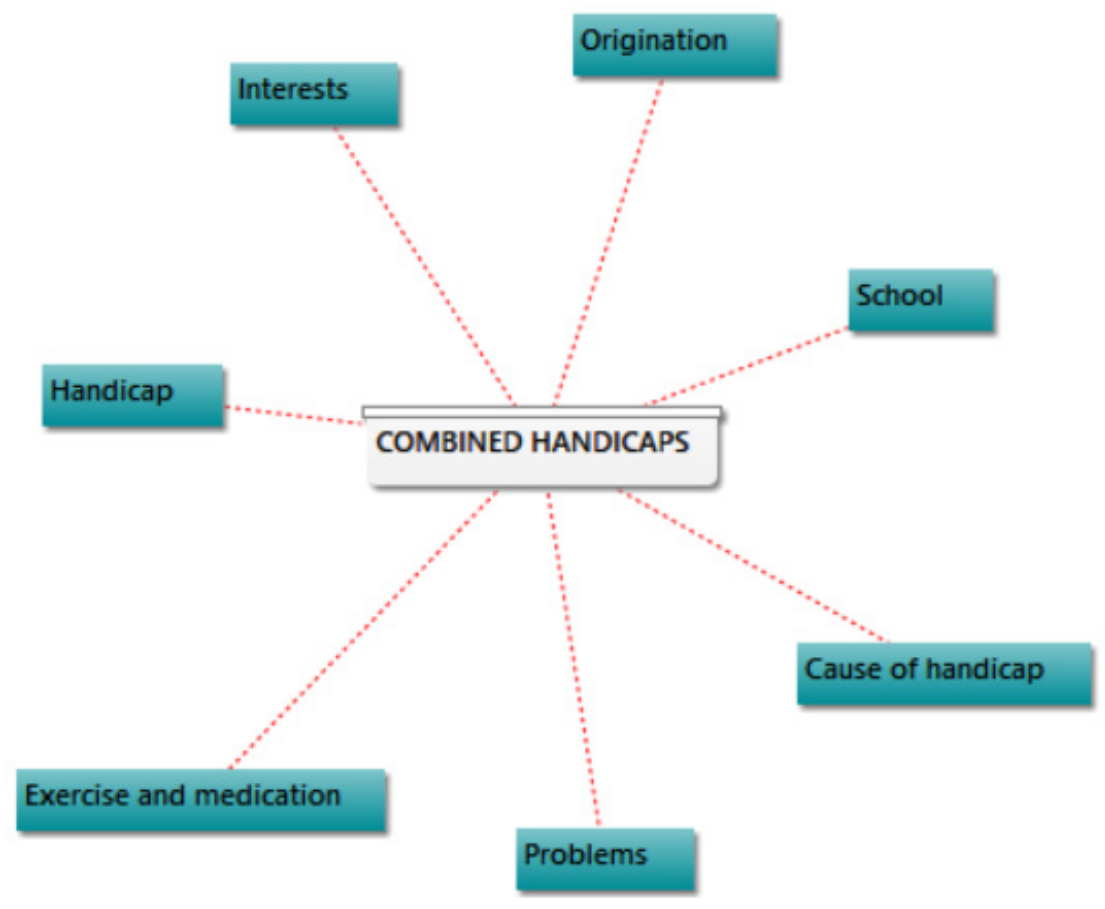

\section{Source: Original research}

In our research sample, these were physical handicaps, most typically based on Central Palsy and other types of handicaps. They were mostly a matter of a combination of the spastic form of Cerebral Palsy and mental retardation, epilepsy or sensory disorders. In all
- either problems with breathing or being an object of ridicule and thirst for the inclusion into the collective.

Given the diagnosis, all the children were supposed to exercise the Vojta Method. The children attend normal or special schools. 


\section{ADHD}

\section{Scheme 6: ADHD}

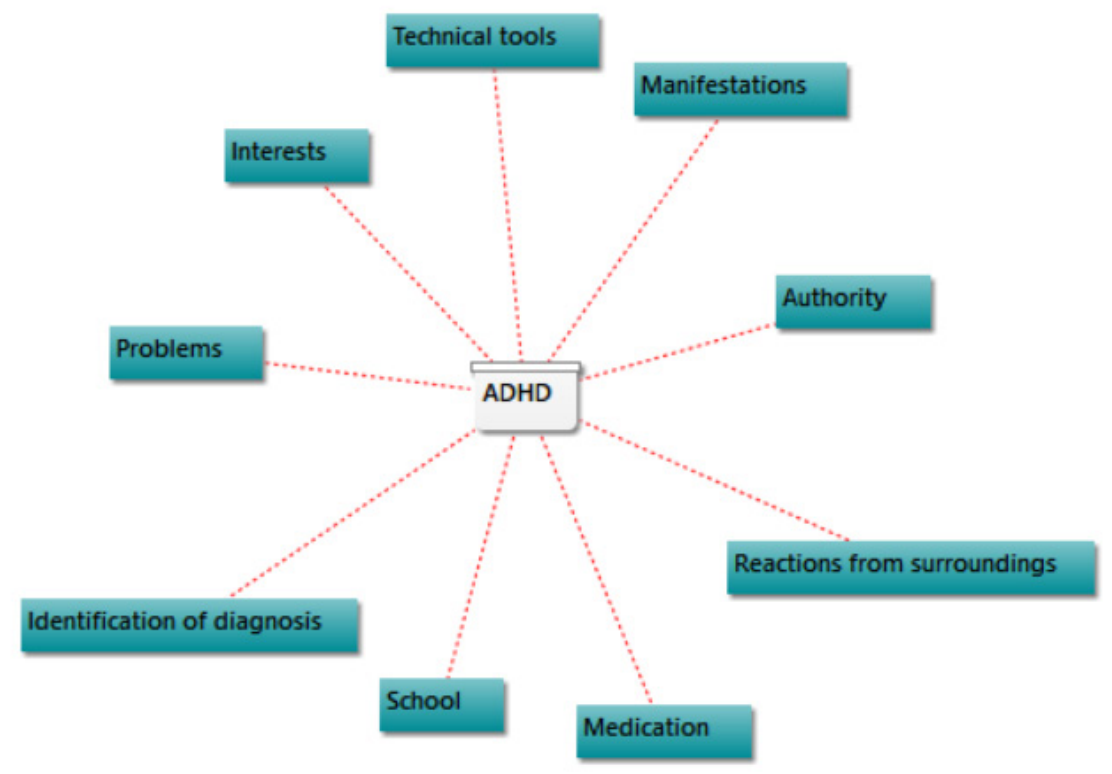

\section{Source: Original research}

Attention disorders syndrome is a further diagnosis characterized by different symptoms. However, it is very frequently accompanied by absent mindedness; aggression; fits of temper; hyperactivity which were mentioned by informants in their answers. The children frequently use a medication, particularly $\mathrm{Ri}$ talin. The informants mentioned misunderstanding from the surroundings and tendency of the society to provide mothers with "well intended advice" how to raise the child.

In children, the diagnostics was implemented at pre-school age. All children of the informants from the sample studied attend the normal schools, either independently or with the help of a pedagogic assistant or personal assistant in the case of the son of informant R26. Technical tools are also frequently employed, such as mobile telephone or tablet and "clever" books. As to the problems, the informants mostly mentioned problems with sleeping, hypersensitivity or disorders in recognition of reading text and dyslexia. Very diverse interests of children were reported, but sport was mentioned frequently. 


\section{Social support}

\section{Scheme 7: Social support}

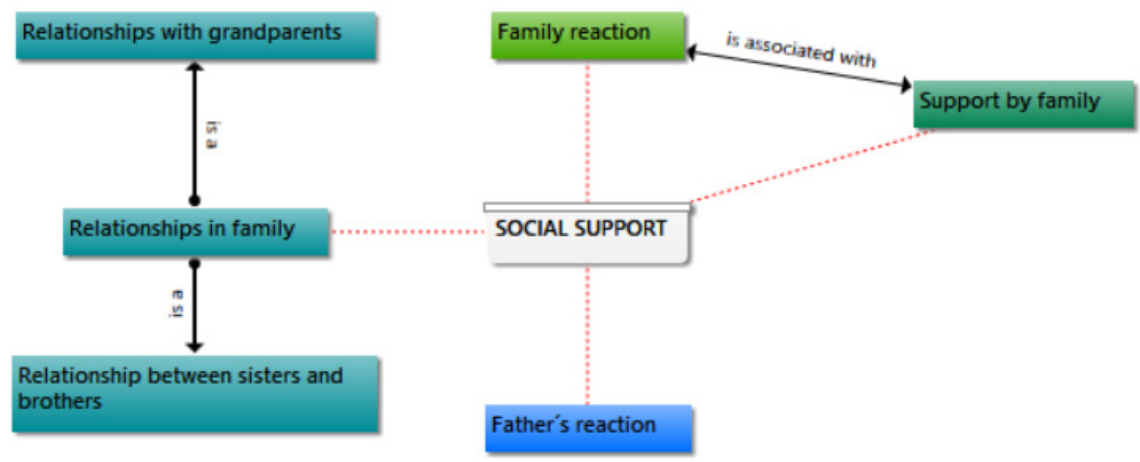

\section{Source: Original research}

Help and support by the family is an important part of the life, particularly of the life of a mother having children with handicaps. In the case of mothers of children in the sample examined, the reaction of the father was entirely positive, in spite of the fact that for the fathers it was difficult to reach reconciliation with the handicap and in some cases, they saddled the mother exclusively with the care and child raising. However, one of fathers has not yet reached the reconciliation with his son's handicap and refuses the diagnosis. On the other hand, informant R33 exclusively takes care of his daughter. Reactions by the family were also rather posi- tive, however, but in certain cases, the wider family is not informed about the handicap, since they would not be able to understand the family and its special requirements. Problems with the reconciliation were also encountered in the case of grandparents. In other cases, informants first met understanding, reproaches or advice how to raise the child. However, there is a positive fact that none of the grandparents completely rejected the grandchild and most of them tried to help and facilitate the family life. If there was a another child in the family, then relationships between sisters and brothers were entirely reported as good. 


\section{Material support by society}

Scheme 8: Material support by society

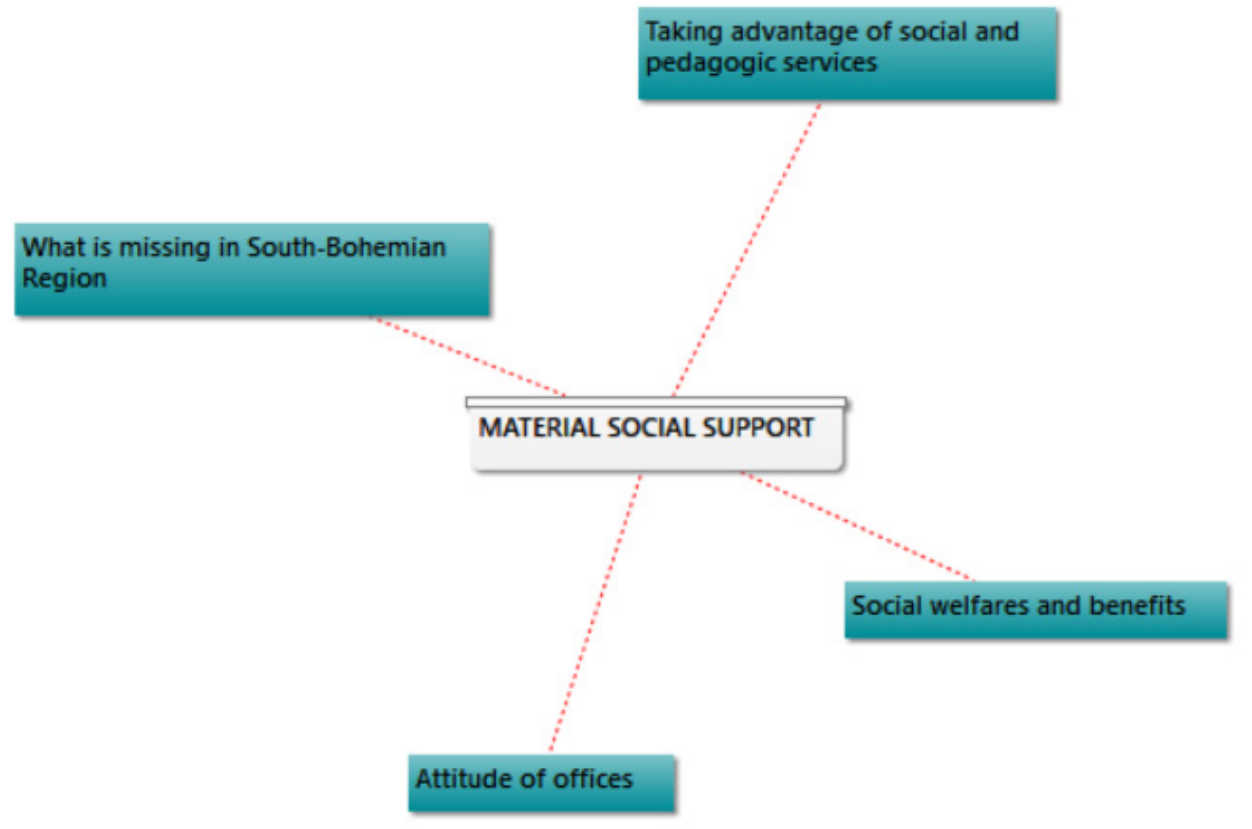

\section{Source: Original research}

In terms of the material social support, social welfare and various social or pedagogic services were mostly employed. This was most frequently a contribution to taking care to varying extents. In certain cases, families also took advantage of the ZTP or ZTP/P card or contribution to mobility or special tools. All the informants, who mentioned the services in the interview, took advantage of some of the wide offering of social and pedagogic services, e.g. Auticentrum, Apla, Arpida, Rolnička or pedagogic-psychological consulting institutions and special pedagogic centers. If the informants mentioned the attitude from offices, then they considered it entirely positively with reservations by informants R15 and R16 only. Different opinions were encountered as to the question of what services are missing in the South-Bohemian Region. In mothers of children with autistic spectrum disorders, wishes were, however, repeatedly expressed, concerning the possibility of relieving services for autistic children or of more free time activities for them. Informant R11 would like to have more services in small towns and villages and informant R18 would appreciate enhanced possibilities of work opportunities on the open as well as protected labor market. However, two informants have not yet felt a lack of services or other activities in the South-Bohemian Region. 


\section{Life with handicapped child}

Scheme 9: Life with handicapped child

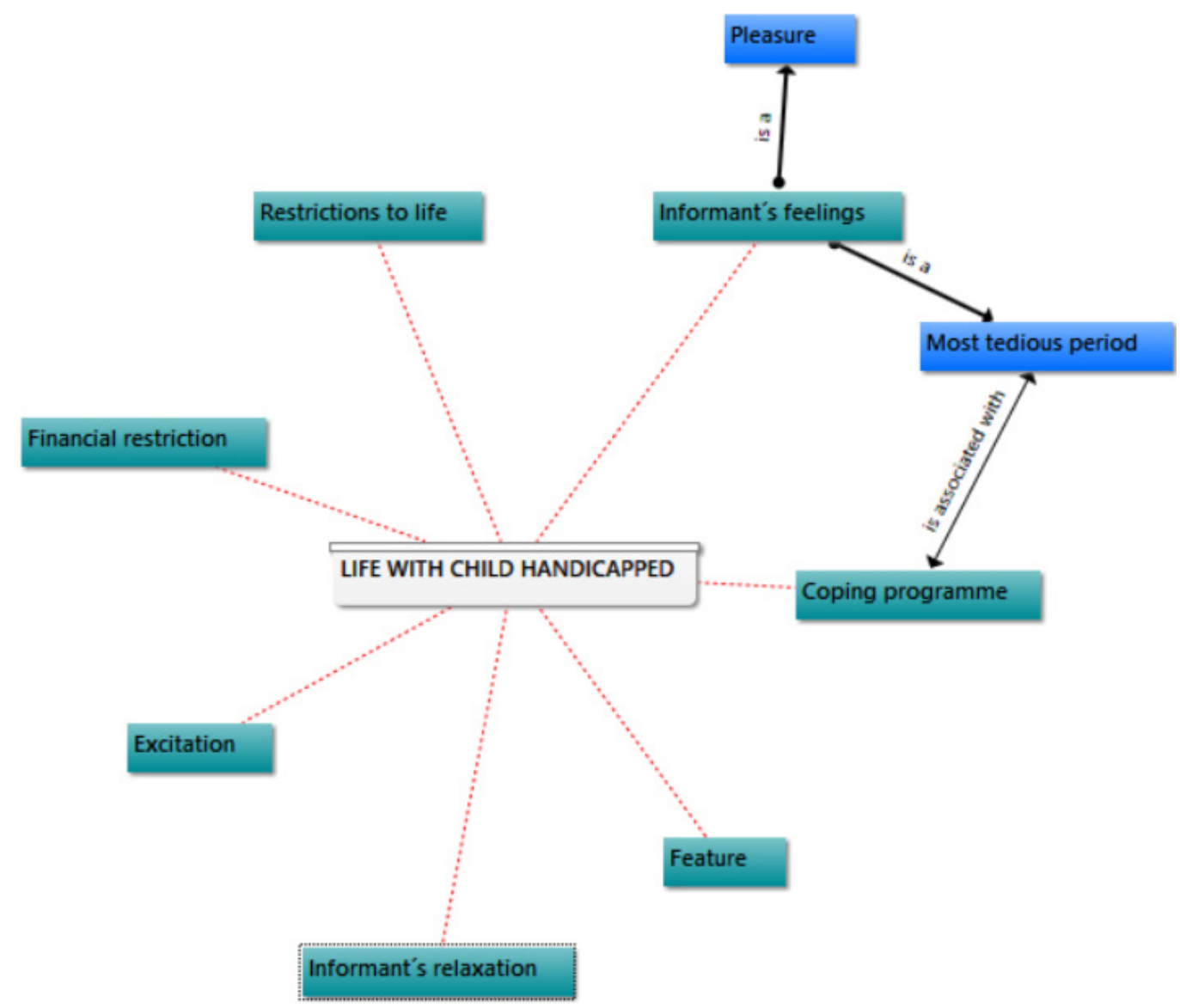

\section{Source: Original research}

Child handicaps bring a considerable mental burden and it is mostly necessary to cope with this situation. Almost all the informants, who mentioned this theme in the interview, passed a coping program. Only informant R3 rather felt an alleviation, and in informants $\mathrm{R} 1$ and $\mathrm{R} 11$, the process of reconciliation has ever been underway. In accordance with facts mentioned by informants, the most complicated period of their life concerned just the reconciliation process associated with the diagnosis and new regimen of life. Other frequent problems were the realization of a diagnosis of fatality or fear of the extent of the handicap. For certain parents, understanding of child's symptoms and problems with healthcare personnel were, however, considerably tedious. Information was frequently repeated that informants are pleased by children having good moods and successes; quiet days; recreation trips; personal interests. According to their words, agitation contrastingly occurs in the case of misunderstanding by the society; child's disease: stress; lack of sleep. Some 
informants also are agitated by fits of temper or loudness by their children. In interviews informants frequently expressed their fear of the future. This most typically resulted from the fear of providing care in the future.

The child's handicap is frequently associated with restrictions to the life and sometimes financial restrictions as reported by the informants in their information. If they pointed out restriction to the child's life, these were mostly cases of social isolation, more worries and loss of friends. However, in some of them, these problems involved a recapitulation of life; pleasure resulting from small successful events; change in considering values of life. However, there are also informants who did not feel any restrictions to life. As far as the financial restrictions or financial problems were concerned, impossibility of finding a quality occupational role with respect to taking care of the child; insufficient financial means for providing the family existence; dependence on social benefits; lack because of only one income in the family were most frequently reported.

\section{Results of the quantitative part of research}

Differences in scores achieved between five groups of respondents (4 diseases + healthy control group) were evaluated for both subscales together with the total score in every questionnaire. A total of 12 tests were thus implemented in five children and five parents from each disease category with the use of three types of PedsQL, with evaluation of the total score and subscales (see Table 1). All the zero hypotheses were refused - in all the (sub)scales, the groups were different one from another in the quality of life.

Two types of PedsQL were evaluated: generic type 4.0 (completed by 5 parents and 5 children in each category) and 2.0 type family module - evaluated only by parents for the last week and last month. The total score and two

Table 1. Results of comparing scores achieved in subgroups studied (Kruskal-Wallis test)

\begin{tabular}{|c|c|c|c|}
\hline Questionnaire - variant & Respondents & (Sub)Scale & P-value \\
\hline \multirow{6}{*}{$\begin{array}{l}\text { PedsQL 4.0 Generic } \\
\text { Core Scale }\end{array}$} & \multirow[t]{3}{*}{ Children } & Physical Health Summary Score & 0.001 \\
\hline & & Psychosocial Health Summary Score & 0.003 \\
\hline & & Total Score & 0.001 \\
\hline & \multirow[t]{3}{*}{ Parents } & Physical Health Summary Score & 0.002 \\
\hline & & Psychosocial Health Summary Score & 0.002 \\
\hline & & Total Score & 0.002 \\
\hline \multirow{3}{*}{$\begin{array}{l}\text { PedsQL 2.0 Family } \\
\text { Impact Module last month }\end{array}$} & \multirow[t]{3}{*}{ Parents } & HRQL Summary Score & 0.005 \\
\hline & & Family Functioning Summary Score & 0.006 \\
\hline & & Total score & 0.002 \\
\hline \multirow{3}{*}{$\begin{array}{l}\text { PedsQL 2.0 Family } \\
\text { Impact Module }\end{array}$} & \multirow[t]{3}{*}{ Parents } & HRQL Summary Score & 0.004 \\
\hline & & Family Functioning Summary Score & 0.024 \\
\hline & & Total score & 0.002 \\
\hline
\end{tabular}

So called omnibus hypothesis was tested. 
subscales, i.e. physical health and psychosocial health were evaluated. In all the tests, the zero hypothesis $\mathrm{H} 0$ was refused, which means that different results were obtained in all the groups of data. The quality of life was thus different.

\section{Paired comparisons by diagnoses}

Results of paired comparisons for five subgroups are shown in Figs. 1-4. Most distinct differences were found between the control subgroup (healthy children) and subgroup of children with autism and ADHD.

Fig. 1. Boxplot of the scores in the Peds Q L 4.0 Generic Core Scale for children - a) Physical Health Summary Score, b) Psychosocial Health Summary Score, c) Total Score. Similar symbols (e.g. $\#, \$, \neq)$ depict significant differences between the two respective groups.
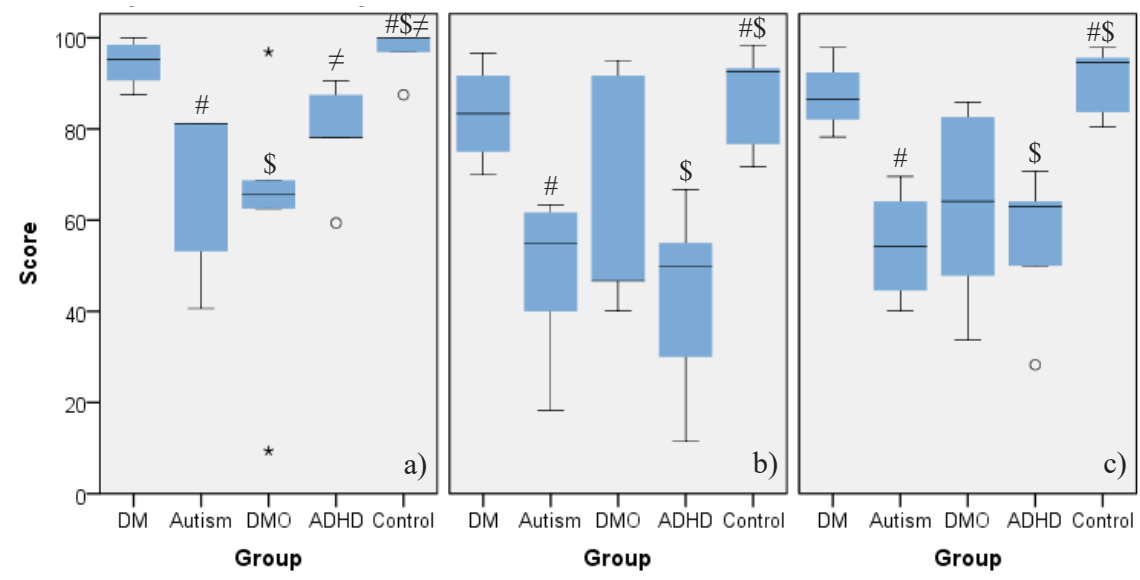

Fig. 2. Boxplot of the scores in the PedsQL 4.0 Generic Core Scale for parents - a) Physical Health Summary Score, b) Psychosocial Health Summary Score, c) Total Score. Similar symbols (e.g. $\#, \$)$ depict significant differences between the two respective groups.
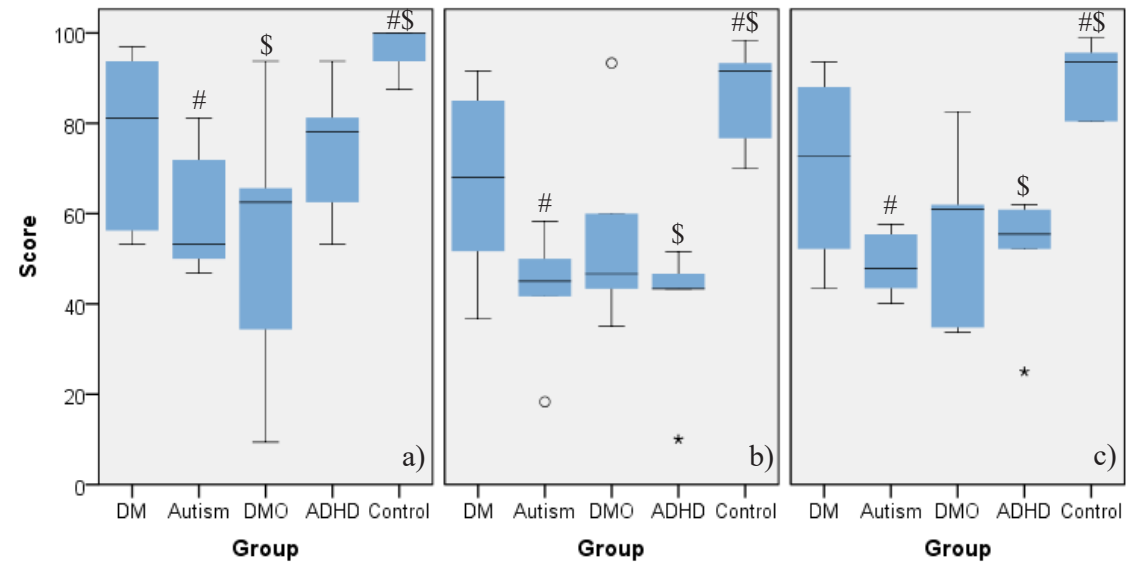
Fig. 3. Boxplot of the scores in the PedsQL 2.0 Family Impact Module for last month - a) HRQQL Summary Score, b) Family Functioning Summary Score, c) Total Score. Similar symbols (e.g. \#, \$) depict significant differences between the two respective groups.
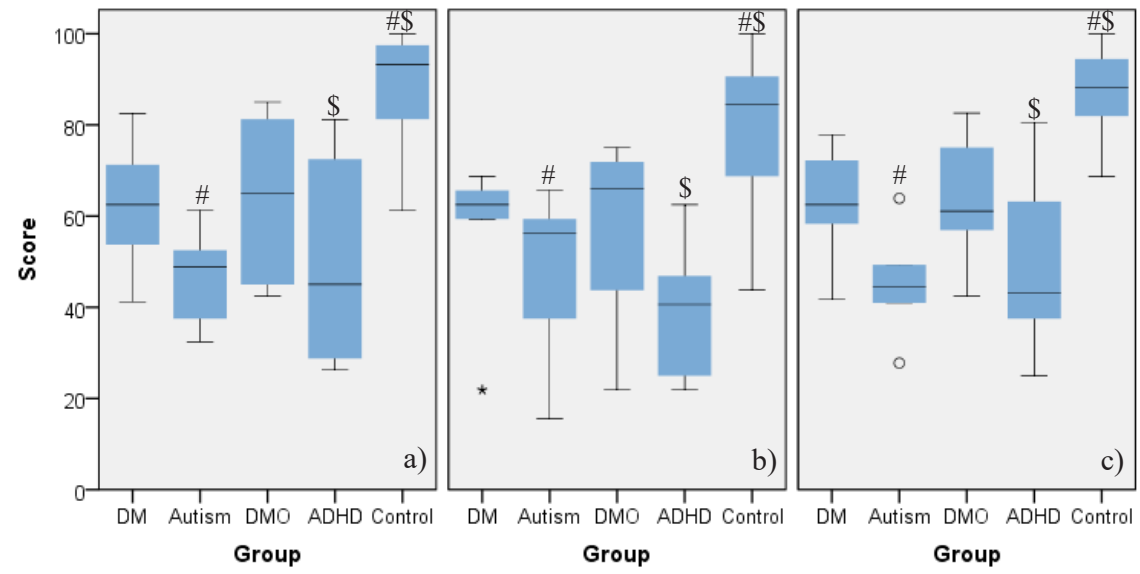

Fig. 4. Boxplot of the scores in the PedsQL 2.0 Family Impact Module for last week - a) HRQ्L Summary Score, b) Family Functioning Summary Score, c) Total Score. Similar symbols (e.g. \#, \$) depict significant differences between the two respective groups.

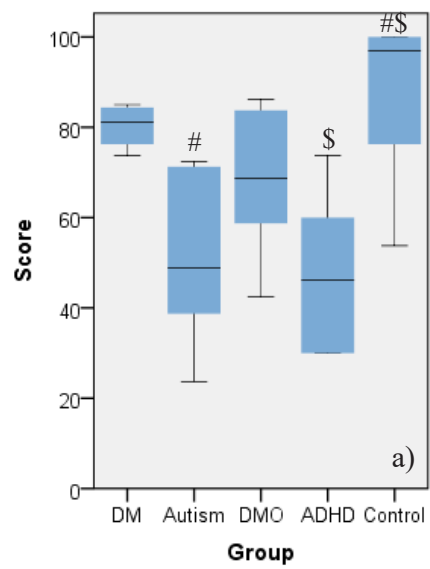

Group

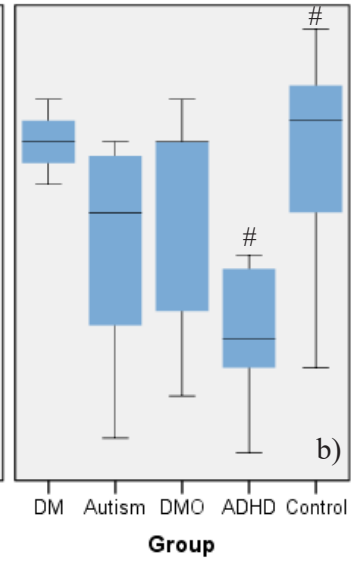

Group

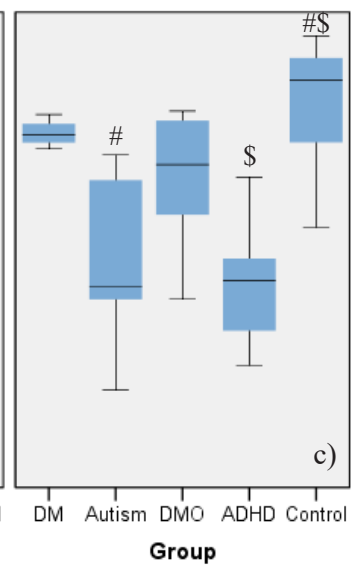

than their parents (Table 2, Graph 5). In the scale of the physical health, a better score in children was found in 14 cases; agreement between children and parents was observed in 10 cases; better score in parents was found in 5 cases. Within the scale of the psychosocial health, children presented better evaluations $19 x$; evaluation in children and parents were in agreement $5 \mathrm{x}$; a higher score was achieved by parents $5 x$. 
Table 2. Results of comparison of scores achieved in children and parents (Wilcoxon Test)

\begin{tabular}{|l|l|c|}
\hline Questionnaire & (Sub)Scale & P-value \\
\hline PedsQL 4.0 Generic Core Scale & Physical Health Summary Score & 0.016 \\
\cline { 2 - 3 } & Psychosocial Health Summary Score & 0.013 \\
\cline { 2 - 3 } & Total Score & 0.004 \\
\hline
\end{tabular}

Figure 5. Differences between the scores of children and their parents in the questionnaire PedsQL 4.0 - a) Physical Health Summary Score, b) Psychosocial Health Summary Score, c) Total Score. Negative scores depict higher children's score compared to their parents', i.e. better quality of life perception by children. Note: zero differences (similar scores of children and parents) are not shown.
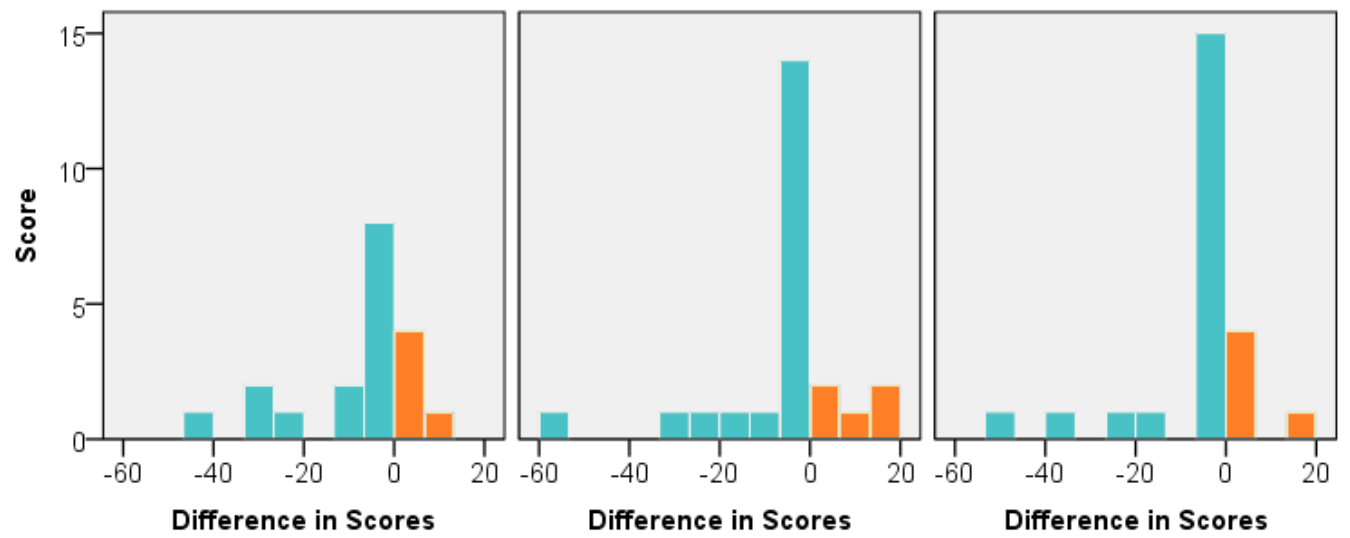

\section{Conclusions}

In 12 tests of PedsQL 4.0 and 2.0 questionnaires, the zero hypothesis was refused and thus, there were differences between values of the quality life among all the groups examined.

In the paired comparison of results of the quality life according to questionnaire PedsQL, the most distinct difference was found between the group of healthy children and group of children with ADHD and autism.

Results of the paired comparison of children with parents document a higher score in children, which means that children consider their quality of life more optimistically compared to their parents.
Children with Diabetes Mellitus have different opinions and there are differences between the quality of life as completed in questionnaires by the child and parent. This results from the fact that the children do not consider their disease as a problem. The reason for this is where the parents of children with Diabetes Mellitus provide essentially everything instead of their children - computing units, supervising regular and balanced food, monitoring sugar levels in the blood, etc.

\section{Anchored theory}

1. The combination of mental handicap, epilepsy and attention disorders is most frequently encountered. 
2. Tedious financial requirement in Diabetes Mellitus associated with purchasing sensors.

3. Fits of temper and aggression hard to manage in children with autism. Tedious taking of care on the part of parents.

4. Problems in the school, in the community of children, retardation, social failure, misunderstanding by surroundings.

5. Taking care by mother, absence on the part of fathers and grandparents in the care.

6. Lack of facilities, particularly in small towns, missing possibility of occupational inclusion in protected workshops.

This research was supported by the Grant Agency of the South-Bohemian University.

\section{Acknowledgements}

The publication was created within GAJU 044/2018 / S ZSF.

\section{References:}

1. BALOUN I, VELEMINSKY M (2018) Validated PedsQLTM evaluation questionnaires the quality of life of children and their families. . Contact. 20(2), 168174. ISSN: 1212-4117.

2. BURESOVA G ET AL (2008) Health related quality of life of children and adolescents with Type 1 diabetes. Neuroendocrinology Letters. 29(6), 1045-1053. ISSN: 0172-780X.

3. CHENG C P (2016) Agreement of children and parents scores on Chinese version of Pediatric Quality of Life Inventory version 4.0: further psychometric development. Applied Research Quality Life.11(3):891-906.

4. ePROVIDE (2017) [online] [cit. 2018-1220]. Online: https://eprovide.mapi-trust. org/
5. FRIESE S (2014) Qualitative Data Analysis with ATLAS. Ti. 2. edition. London: Sage Publications Ltd. 279 p. ISBN: 9781-44628-203-8.

6. GURKOVA E (2011) Quality of life assessment: for clinical practice and nursing research. Praha: Grada. ISBN: 97880-247-3625-9.

7. The WHOQOL Group. (1997) The World Health Organization Quality of Life Assessment (WHOQOL): Measuring quality of life. [online]. [cit. 2018-12-20]. Online: http://www.who.int/mental_health/media/68.pdf

8. VARGHA A, DELANEY H D (1998) The Kruskal-Wallis Test and Stochastic Homogeneity. Journal of Educational and Behavioral statistics. 23(2), 170-92. ISSN: 10769986

9. VARNI J W (1998) The PedsQL $L^{T M}$ Measurement Model for the Pediatric Quality of Life Inventory ${ }^{T M}$. [online]. [cit. 201811-11]. Online: https://www.pedsql.org/ index.html

10. VARNI J W, PedsQL (2017) [online] [cit. 2017-03-27]. Online: http://www.pedsql. org/

11. VARNI J W (2004) Pediatric Quality of Life Inventory ${ }^{\mathrm{TM}}$.[online]. [cit. 2019-0105] Online: http://www.mapiresearch. fr/t_03_serv_dist_Cduse_pedsql.htm

12. VARNI J W, SEID, KURTIN P S (2001) PedsQL 4.0: reliability and validity of the Pediatric Quality of Life Inventory version 4.0 generic core scales in healthy and patient populations. Medical care. 39(8), 800-12.

13. VARNI J W ET AL. (2003) The Peds $Q L$ in type 1 and type 2 diabetes: reliability and validity of the Pediatric Quality of Life Inventory Generic Core Scales and type 1 Diabetes Module. Diabetes Care. 26(3):631-637. 